\title{
Voltage Feed-forward Performance in Stationary Reference Frame Controllers for Wind Power Applications
}

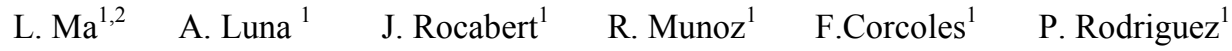 \\ 1. Renewable Electrical Energy System, Technical University of Catalonia, Barcelona, Spain \\ 2. School of Electrical Engineering, Beijing Jiao Tong University, Beijing, China, 100044 \\ luna@ee.upc.edu, 05117293@bjtu.edu.cn
}

\begin{abstract}
In order to improve the connected current and the response speed of the controller, stationary reference frame control strategy with proportional resonant $(P-R)$ controller due to its high dynamic and good harmonic compensation performance characteristics was already used in many different DG applications. This paper introduced an additional stationary reference frame control strategies with voltage feed-forward method. By using this method, both the quality of grid connected current and the dynamic performance are improved, which also validated by experiments.
\end{abstract}

\section{INTRODUCTION}

Recently all kinds of distributed generation (DG) systems were developed rapidly. Grid connected inverters as one of the most important parts in DG systems, their current loop controllers are always the investigated focus.

Nowadays, the stationary reference frame control strategy based on Proportional Resonant (P-R) three phases current controller was already widely used by many kinds of applications due to its high dynamic characteristics ${ }^{[1-3]}$. Compared with conventional synchronous reference frame controller, the P-R controller has many advantages including: eliminates $a b c$-to- $d q$ and $d q$-to- $a b c$ frame transformations which significantly reduces computation burden; removes PLL errors; easy to add the low order harmonic compensation especially the P-R controller could improve the response to unbalanced faults ${ }^{[4]}$.

Due to P-R controller could achieve a very high gain around the given resonance frequency, thus being capable to eliminate the steady-state error when this controller tracking sinusoidal reference, which could be suitable for the using of stationary reference frame control strategy ${ }^{[5]}$. Moreover, high dynamic characteristics of the stationary reference frame control strategy based on PR controller made it used in many applications which demanded fast response speed such as grid faults ride through ${ }^{[6]}$.

But just due to the high response to the given frequency, the conventional P-R controller usually saves using voltage feed-forward block. But actually when voltage feed-forward function was added, it could even more improve the response speed to the grid disturbance. The problem is that: when using the voltage of the PCC (point of common coupling) as feed-forward voltage, the interaction of the nonlinear load harmonics with the comparable grid impedances creates voltage distortions at the PCC which in turn affects the current loop control. Especially the $3^{\text {rd }}$ voltage harmonic distorts the output current significantly when instant voltage feed-forward was accepted.

This paper proposes a new method with positive sequence grid voltage feed-forward (or PCC voltage feed-forward) instead of instant voltage feed-forward which could restrain the influence to the current controller caused by the nonlinear load harmonics. By using positive sequence voltage feedforward, the response speed of the current controller was improved meanwhile the output current quality was much better compared with using instant voltage feed-forward. This method also validated by $3 \mathrm{~kW}$ experiments.

\section{PROPORTIONAL RESONANT (P-R) CONTROLLER AND STATIONARY REFERENCE FRAME CONTROL STRATEGY}

The proportional resonant (P-R) controller was proposed and developed during last decade, firstly used in the area of active power filter applications ${ }^{[7]}$. Then it was introduced to single phase and three phase current control ${ }^{[8-9]}$.

The main idea of P-R controller is that: adding two fixed frequency closed loop poles in order to create the resonance at the given frequency, which could greatly increase the gain of that frequency (actually in theory the gain could arrive to infinity). By using this method, the P-R controller could track given frequency sinusoidal reference without steady errors, overcome the well-known drawback of P-I controller.

It also could understand in another way: in three phase synchronous reference frame control, the P-I control could track the constant reference without state errors, that because it transformer $a b c$-to- $\alpha \beta$-to- $d q$ by using the rotating angles. In the case of P-R controller, it also need the resonant frequency. These two controllers are the same in mathematical essence, just the P-R controller saved the using of reference frame transformation.

There are a lots of paper introduced P-R controller ${ }^{[1-9]}$, here just gave the basic equation as equation (1) and implementing scheme in Fig. 2 . 


$$
u_{\text {output }}(s)=\xi_{\text {error }}(s) \cdot\left(K_{P}+\frac{K_{R} \cdot s}{s^{2}+\omega_{0}^{2}}\right)
$$

$$
\begin{aligned}
& G_{\mathrm{PI}}(s)=K_{\mathrm{P}}+\frac{K_{\mathrm{I}}}{s} \\
& G_{\mathrm{PR}}(s)=K_{\mathrm{P}}+\frac{K_{\mathrm{R}} \cdot s}{s^{2}+\omega_{0}{ }^{2}}
\end{aligned}
$$

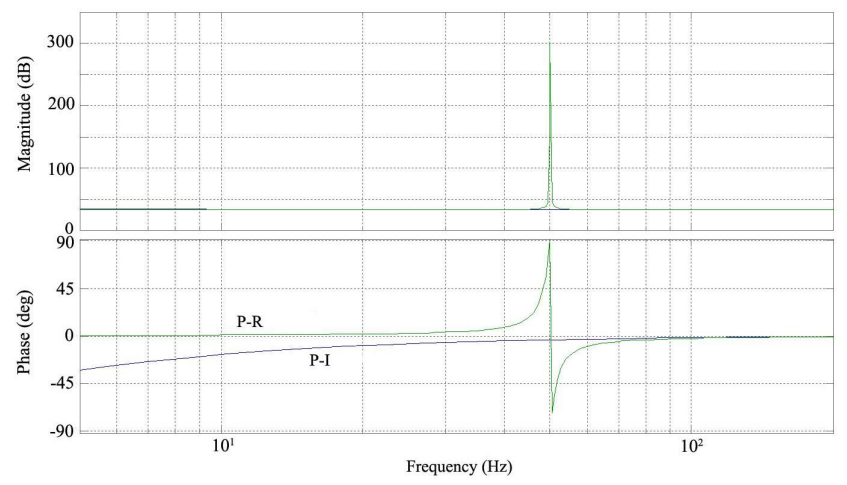

Figure 1: Open-loop Bode plot of PR and PI controller

Fig. 1 shows the open loop Bode plot of PR and PI controllers based on the open loop equation (2) and (3). In the comparison, it could clearly see that at the resonant frequency point, the open loop gain of P-R controller is increasing greatly.

In the reference [5], the digital implementing method of P$\mathrm{R}$ controller was also given. It was completed by a GI (generalized integrator) second order controller ${ }^{[10]}$. The implementing scheme is also shown in the Fig. 2 dashed block.

$$
\frac{y(s)}{u(s)}=\frac{s}{s^{2}+\omega_{0}{ }^{2}} \Leftrightarrow\left\{\begin{array}{c}
y(s)=\frac{1}{s}[u(s)-v(s)] \\
v(s)=\frac{1}{s} \cdot \omega^{2} \cdot y(s)
\end{array}\right.
$$

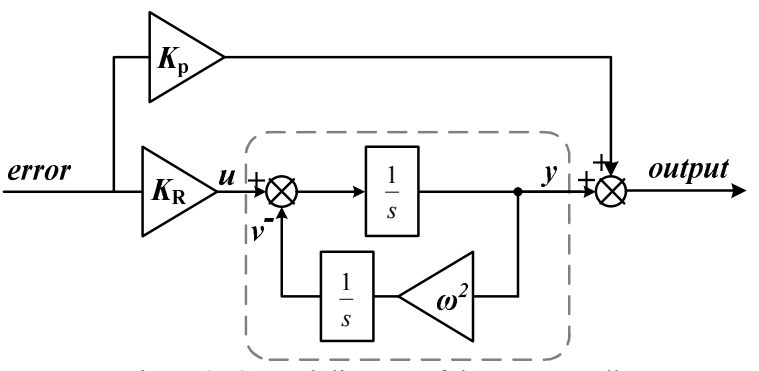

Figure 2: Control diagram of the PR controller

By using the programming language, with discrete signal to implement equation (4) follow as (5) where $T_{\mathrm{s}}$ is the sampling period:

$$
\left\{\begin{array}{l}
y_{k}=y_{k-1}+T_{\mathrm{s}} \cdot\left(u_{k-1}-v_{k-1}\right) \\
v_{k}=v_{k-1}+T_{\mathrm{s}} \cdot \omega^{2} \cdot y_{k}
\end{array}\right.
$$

Equation (1) gives the harmonic differential between original signal and positive sequence signal. Table 1shows the harmonic elimination of positive sequence, where it is could be found that the 3rd harmonic in positive sequence was totally eliminated. Actually the function of transformation original signal to positive sequence signal is seems like a non-delay filter.

$$
v_{a b c}^{+n}=C^{n} v_{a b c}{ }^{n}\left\{\begin{array}{c}
\left|C^{n}\right|=\sqrt{\frac{1}{2}\left[1+\sin \left(n \frac{\pi}{2}\right)\right]} \\
\angle C^{n}=\operatorname{sgn}(n) \tan ^{-1} \frac{\cos \left(n \frac{\pi}{2}\right)}{2\left|C^{n}\right|^{2}}
\end{array}\right.
$$

TABLE 1: Harmonic comparison (Original signal is $1\left\llcorner 0^{\circ}\right.$ )

\begin{tabular}{c|c}
\hline Order & Positive Sequence \\
\hline 1 & $1\left\llcorner 0^{\circ}\right.$ \\
2 & $0.707\left\llcorner-45^{\circ}\right.$ \\
3 & 0 \\
4 & $0.707\left\llcorner 45^{\circ}\right.$ \\
5 & $1\left\llcorner 0^{\circ}\right.$ \\
\hline
\end{tabular}

Paper [11] gives the detailed method how to transformer original signal to positive sequence in stationary reference frame, equation (7)-(12) shows the main processes:

$v_{a b c}=\left[\begin{array}{lll}v_{a} & v_{b} & v_{c}\end{array}\right]^{T}$

$v_{a b c}^{+}=\left[\begin{array}{lll}v_{a_{-} p o s} & v_{b_{-} p o s} & v_{c_{-} p o s}\end{array}\right]^{T}=\left[T_{+}\right] v_{a b c}$

$\left[T_{+}\right]=\frac{1}{3}\left[\begin{array}{ccc}1 & a^{2} & a \\ a & 1 & a^{2} \\ a^{2} & a & 1\end{array}\right] \quad a=e^{-j \frac{2 \pi}{3}}$

$v_{\alpha \beta}=\left[\begin{array}{ll}v_{\alpha} & v_{\beta}\end{array}\right]^{T}=\left[T_{\alpha \beta}\right] v_{a b c}$

$\left[T_{\alpha \beta}\right]=\frac{2}{3}\left[\begin{array}{ccc}1 & -\frac{1}{2} & \frac{1}{2} \\ 0 & \frac{\sqrt{2}}{3} & -\frac{\sqrt{2}}{3}\end{array}\right]$

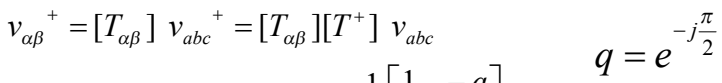

\section{Positive SeQuence VOltage}

$$
=\left[T_{\alpha \beta}\right]\left[T^{+}\right]\left[T_{\alpha \beta}\right]^{-1} v_{\alpha \beta}=\frac{1}{2}\left[\begin{array}{cc}
1 & -q \\
q & 1
\end{array}\right] v_{\alpha \beta} \quad q=e^{2}
$$




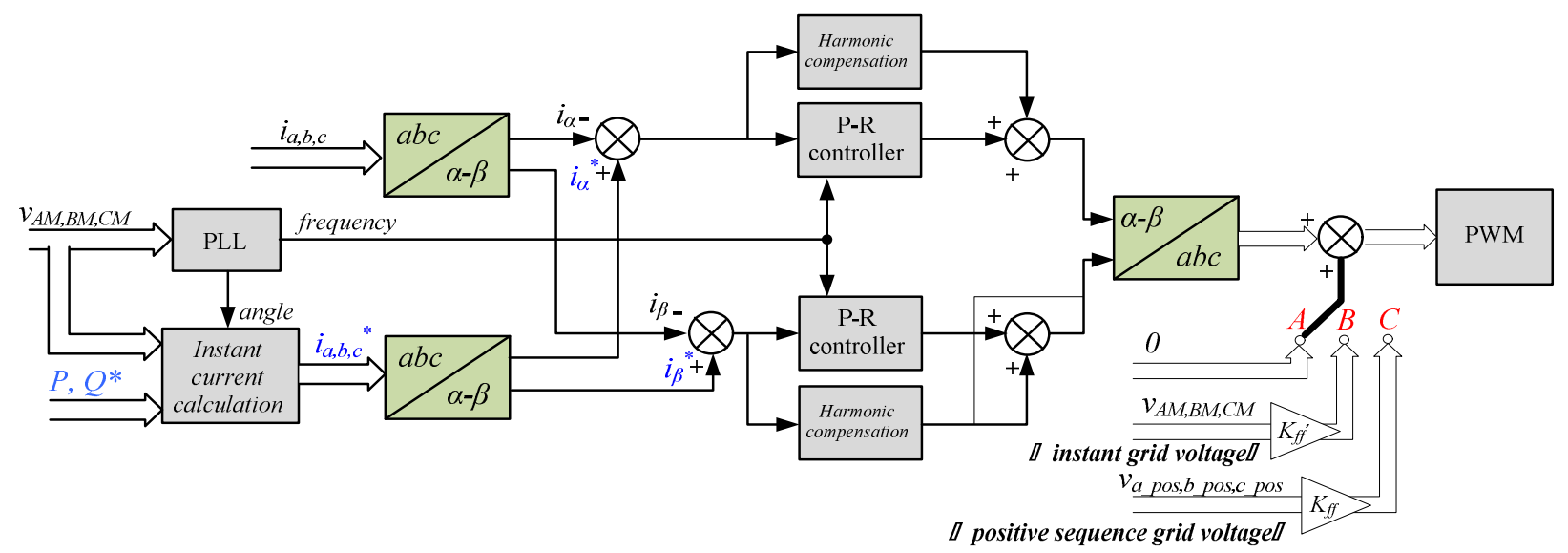

Figure 3: Stationary reference frame control scheme.

\section{STATIONARY REFERENCE FRAME CONTROL SCHEME WITH VOLTAGE FEED-FORWARD}

Fig. 3 shows the stationary reference frame control scheme with voltage feed-forward function. This control scheme is used for a grid connected inverter control as Fig.4 and Fig.5 shown.
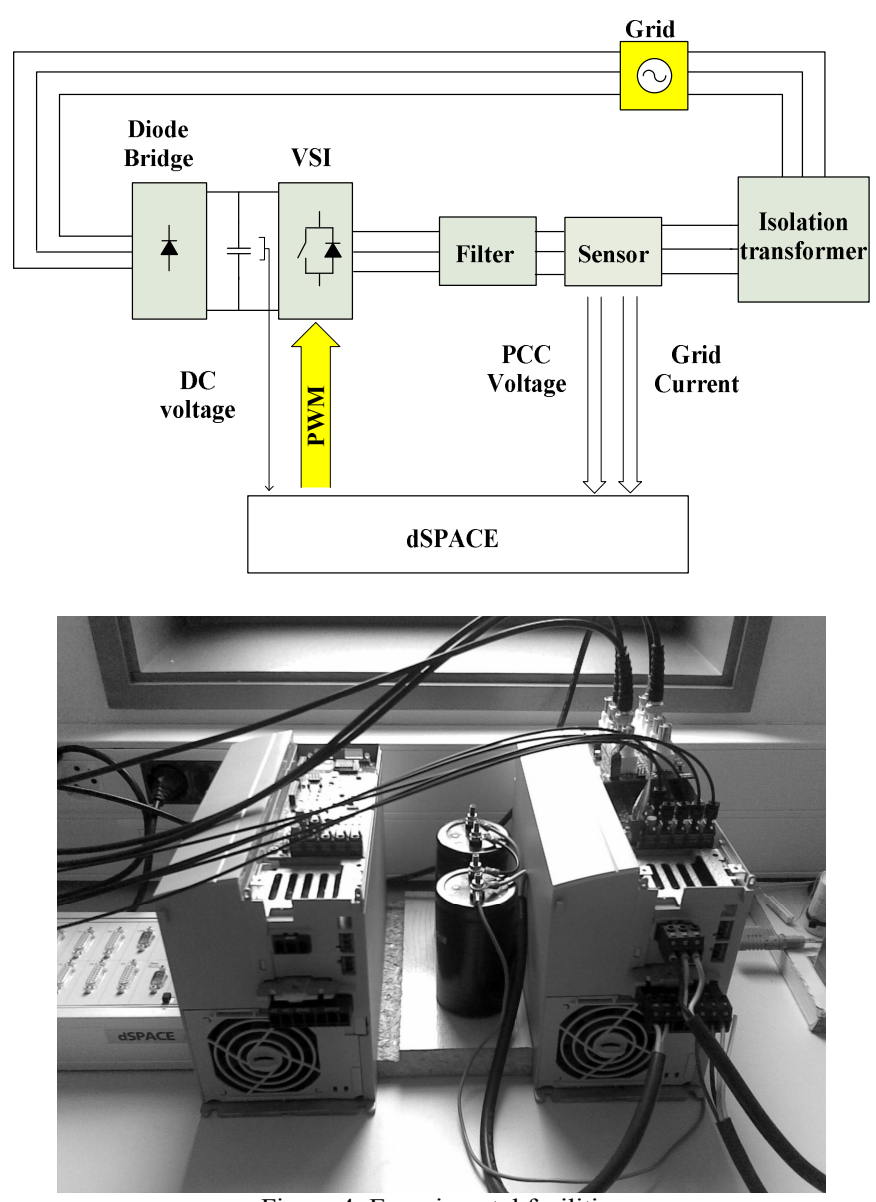

Figure 4: Experimental facilities

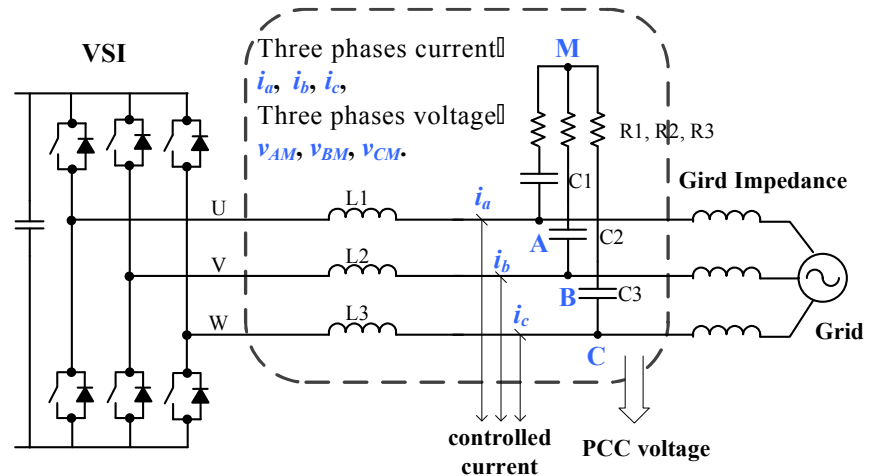

Figure 5: LC filter and sensors position.

In Figure 3, there are three voltage feed-forward paths: no feed-forward; instant voltage feed-forward with proportional factor $K_{\mathrm{ff}}$ '; positive sequence voltage feed-forward with proportional factor $K_{\mathrm{ff}}$. By changing the proportional factor $K_{\mathrm{ff}}$ from 0 to 1 , it determines how the feed-forward part plays the role in the control.

Some papers pointed out that if the grid voltage feedforward function is accepted, it leads in turn to the presence of the grid-voltage background harmonics in the current waveform. Thus, a poor THD of the current will typically be obtained ${ }^{[5]}$. However, the voltage feed-forward function could improve the response speed to the grid voltage disturbance. Also, it's useful for starting the system avoiding the current overshoot.

In order to improve the dynamic character of the controller, the author firstly involved the instant voltage feed-forward function, but when the grid has heavy nonlinear loads, the low order harmonics, especially $3^{\text {rd }}$ order harmonics influence the current quality badly as [5] referred.

In the case of that, then the positive sequence voltage feedforward method was accepted, the positive sequence does not change the fundamental voltage, but clear the influence 
caused by the $3^{\text {rd }}$ order harmonics, also weakens other low order harmonics' influence.

As it mentioned up, the voltage feed-forward function could improve the dynamic character of controller but decrease the quality of current at the same time. The proportional factor $K_{\mathrm{ff}}$ is accepted to balance these two point: dynamic character or current quality. When the current quality cannot achieve the demand of the code, low $K_{\mathrm{ff}}$ should be accepted.

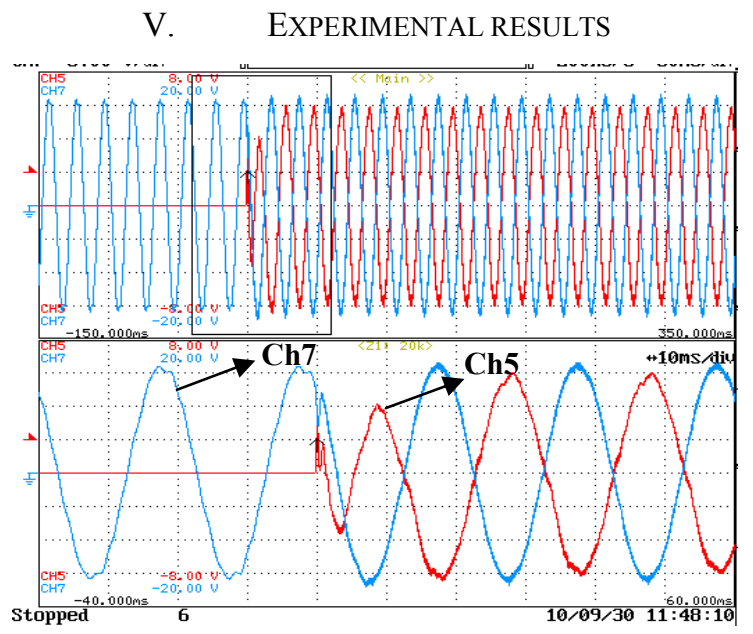

Figure 6: Waveforms without feed-forward Ch5: ia (2 A/div) $\square$ Ch7: vAM (200 V/div)

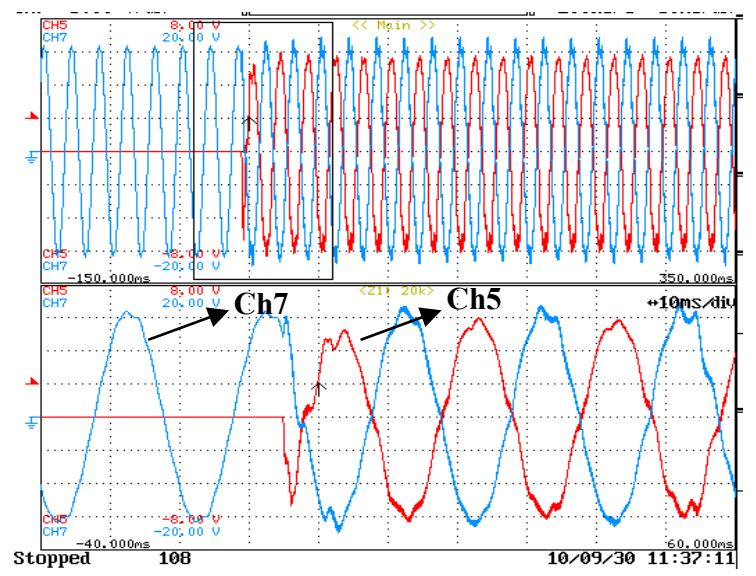

Figure 7: Waveform with instant $\mathrm{v}$ feed-forward $\mathrm{K}_{\mathrm{ff}}=0.9$ Ch5: ia (2 A/div) $\square \mathrm{Ch} 7$ : vAM (200 V/div)

Fig 6, 7, 8 shows the $3 \mathrm{~kW}$ step response experimental results, the PCC voltage was distorted before the inverter started to work.

Fig.6 shows that without feed-forward function, the harmonics of injecting current is low. Whereas Fig.7 shows when instant voltage was accepted, the current quality was decrease a lot even using $K_{\mathrm{ff}}=0.9$ (when $K_{\mathrm{ff}}=1.0$, the system cannot work steadily), but the response speed is faster than Fig.6.

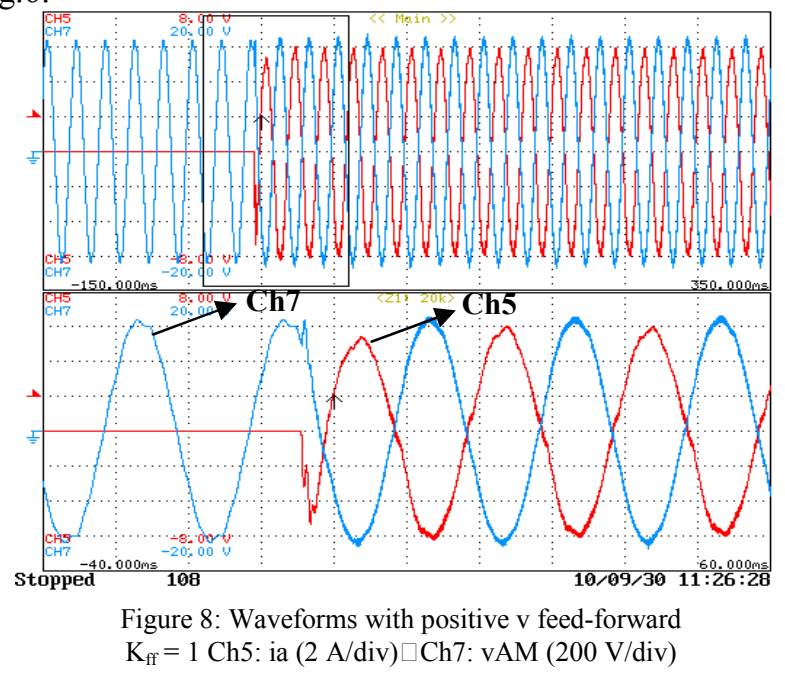

Compared with Figure 6 and 7, it could find that by using positive sequence feed-forward the controller response speed was faster than no feed-forward and current quality was better than instant voltage feed forward as shown in Fig.8.

\section{CONCLUSIONS}

This paper expands upon the knowledge of proportional resonant (P-R) current controller based on stationary frame, by adding a voltage feed-forward part with proportional factor to improve the response speed to the voltage disturbance.

In doing so, the instant voltage feed-forward method was proved that when the instant voltage of the PCC was feedforward, the interaction of the nonlinear load harmonics with the comparable grid impedances creates voltage distortions at the PCC which in turn affects the current loop control and influent the output current quality. Then a new positive sequence voltage feed-forward method was introduced. By using this method, the voltage distortion of PCC caused by both nonlinear load and current injection were restrained at the same time guaranteed the output current quality. It was also validated by $3 \mathrm{~kW}$ step response experiments with satisfied performance. This grid current injecting control work was a starting part of the grid faults ride through project, in the future, more tasks connected with stationary controller and grid faults ride through will be carried on.

\section{ACKNOWLEDGMENT}

. This work was supported by the Ministerio de Educacion y Ciencia of Spain under Project ENE2008-06588-C0403/ALT. 


\section{REFERENCES}

[1] F. Blaabjerg, R. Teodorescu, M. Liserre, A.V Timbus, "Overview of Control and Grid Synchronization for Distributed Power Generation Systems." IEEE Transactions on Industrial Electronics, vol. 53, no.5, pp. 1398-1409, Oct. 2006.

[2] Bhowmik S, Spee R, Enslin J H R, "Performance optimization for doubly fed wind power generation systems." IEEE Transactions on Industry Applications, nol.35, no.4, pp.949-958, Aug.1999.

[3] Timbus, A.V.; Ciobotaru, M.; Teodorescu, R.; Blaabjerg, F., "Adaptive resonant controller for grid-connected converters in distributed power generation systems."Applied Power Electronics Conference and Exposition, APEC '06. 2006, pp.1-6.

[4] J.G.Hwang, P.W. Lehn, M.Winkelnkemper, "A Generalized Class of Stationary Frame-Current Controllers for Grid-Connected AC-DC Converters." IEEE Transactions on Power Delivery, vol. 25, no. 4, pp. 2742 - 2751, Oct. 2010.

[5] R. Teodorescu, F. Blaabjerg, U. Borup, et al, "A new control structure for grid-connected LCL PV inverters with zero steady-state error and selective harmonic compensation," in Applied Power Electronics Conference and Exposition, APEC '04. Nineteenth Annual IEEE, 2004 pp. 580-586.

[6] A. Petersson , L. Harnefors , T. Thiringer "Evaluation of current control methods for wind turbines using doubly-fed induction machines." IEEE Transactions on Power Electronics , vol. 20, no. 1, pp. 227-235, Jan. 2005.

[7] P. Mattavelli, "A Closed-Loop Selective Harmonic Compensation for Active Filters." IEEE Transactions on Industrial Electronics, vol. 37, no.1, pp. 81-89, Jan. 2001

[8] Shuitao Yang, Qin Lei, Peng, F.Z., Zhaoming Qian. "A robust control scheme for grid-connected voltage source inverters" Applied Power Electronics Conference and Exposition (APEC), 2010 Twenty-Fifth Annual IEEE, 2010, pp.1002-1009.

[9] R. Teodorescu, F. Blaabjerg, M. Liserre, et al, "Proportional-resonant controllers and filters for grid-connected voltage-source converters." IEE Proceedings Electric Power Applications, vol.153, no.5, pp. 750762, Oct. 2006

[10] Yuan X., Merk W., Stemmler H., et al. "Stationary-Frame Generalized Integrators for Current Control of Active Power Filters with Zero Steady-State Error for Current Harmonics of Concern under Unbalanced and Distorted Operating Conditions" IEEE Transactions on Industry Application, vol.38, no.2, pp.523-532, Aug. 2002

[11] P. Rodriguez, R. Teodorescu, I. Candela, et al, "New Positive-sequence Voltage Detector for Grid Synchronization of Power Converters under Faulty Grid Conditions," Power Electronics Specialists Conference, PESC '06. 37th IEEE, 2006, pp.1-7. 